\title{
A REVISTA FOTOCRONOGRAFIAS E OS DESAFIOS DA CONSTRUÇÃO DE PERIÓDICOS DIGITAIS PARA PUBLICAÇÃO DE FOTOETNOGRAFIAS ${ }^{1}$
}

\author{
The fotocronografias joumal and the challenges of building digital journals for the \\ publication of photoetnographies
}

Matheus Cervo ${ }^{2}$

\section{http://dx.doi.org/10.52641/cadcaj.v7i1.658}

Resumo: Esse artigo aborda as especificidades da construção de periódicos científicos digitais para publicação de fotoetnografias no Brasil. Parte-se da compreensão de que, nas últimas duas décadas, as revistas acadêmicas online foram desenvolvidas principalmente para publicação de artigos científicos escritos, havendo uma lacuna de pesquisa no que se refere às produções universitárias que são feitas com outras mídias - como a fotografia. Assim sendo, esse artigo contribui para suprir essa lacuna com um relato sobre a fundação e desenvolvimento da revista Fotocronografias pelo Banco de Imagens e Efeitos Visuais (BIEV/UFRGS), um periódico que possui cinco anos de existência e que tem como foco a publicação seriada de fotoetnografias em dossiês temáticos. Entendendo que houve (e ainda há) muitos desafios comunicacionais e informacionais para criação e manutenção de um periódico como esse, criou-se esse relato a fim de demonstrar quais foram os problemas enfrentados e quais ainda são debatidos pela Comissão Editorial responsável. A metodologia para a produção deste artigo foi a Etnografia da Duração, visto que este relato não é uma redação que contém fatos objetivos narrados de forma imparcial, mas sim múltiplas memórias narradas pelo autor deste artigo.

Palavras-chave: Periódico Científico; Revista Acadêmica; Antropologia Visual; Etnografia da Duração.

\begin{abstract}
This article addresses the details of the construction of digital scientific journals for publishing photoethnographies in Brazil. It starts with the understanding that, in the last two decades, online academic journals were developed mainly for the publication of written scientific articles, which leads to the existence of a research gap with regard to university productions that are made with other types of media - such as photography. Therefore, this article contributes to fill this gap with a report about the foundation and the development of the journal "Fotocronografias" by the Image Bank and Visual Effects (BIEV / UFRGS), a periodical that has five years of existence and that focuses on serial publication of photoethnographies in thematic dossiers. Understanding

\footnotetext{
${ }^{1}$ Esse artigo foi escrito com apoio e comentários da professora Ana Luiza Carvalho da Rocha e do doutorando Fabrício Barreto (ambos membros da Comissão Editorial da Fotocronografias), e essa nota de rodapé foi aqui colocada como forma de agradecimento.

2 Cientista Social formado com ênfase em Antropologia pela Universidade Federal do Rio Grande do Sul (UFRGS). Atual mestrando do Programa de Pós-Graduação em Comunicação (PPGCOM) da mesma universidade. Atua como membro do Banco de Imagens e Efeitos Visuais (BIEV) e do Grupo de Pesquisa em Jornalismo Ambiental. É membro da Comissão Editorial da revista Fotocronografias e é co-criador do repositório digital de Antropologia Urbana do grupo BIEV. Orcid: https://orcid.org/0000-0002-6913-802X Lattes: http://lattes.cnpq.br/8290548520385605 Email: cervomatheus@gmail.com
} 
that there were (and still are) many communicational and informational challenges for the creation and maintenance of a journal like this, this report was created in order to demonstrate what were the problems faced and which are still debated by the responsible Editorial Commission. The methodology for producing this article was Ethnography of Duration, since this report is not a writing that contains objective facts impartially narrated, but rather it has multiple memories narrated by the author of this article.

Keywords: Scientific Journal; Academic Journal; Visual Anthropology; Ethnography of Duration. 


\section{INTRODUÇÃO}

Esse artigo pretende discutir a questão da comunicação e preservação do conhecimento produzido nas universidades brasileiras pela via de periódicos científicos. Estritamente, almeja-se refletir sobre a especificidade dos periódicos que enfocam a Antropologia Visual e, principalmente, a fotoetnografia.

Nas últimas décadas, a criação de revistas nas disciplinas científicas mudou consideravelmente sua forma de produção devido à emergência dos suportes digitais. Se antes havia a predominância do espaço livresco impresso em papel nos periódicos científicos, é difícil ver atualmente alguma dessas revistas que não tenha ao menos uma duplicação de seu formato físico em ambiente digital. Contudo, para além dessa duplicidade, percebe-se que a passagem do analógico ao virtual não implica somente uma transposição fidedigna de um meio a outro, mas também provoca a transformação de certas questões infocomunicacionais ${ }^{3}$ da abertura desses dados na internet.

São diversas as problemáticas que são estudadas sobre a criação de periódicos eletrônicos, mas uma revisão bibliográfica. ${ }^{4}$ mostrou que ainda não existem muitas publicações que falem sobre os acervos fotográficos que são fruto de pesquisa universitária e que são comunicados e preservados em artigos científicos de periódicos na Antropologia. Predominantemente, os diferentes campos do saber no ocidente criam sua autoridade científica a partir da escrita, tornando esse suporte hegemônico e aparentemente neutro na criação de conhecimento (ECKERT; ROCHA, 2020). Porém, essa hegemonia causa a falta de reflexão sobre o suporte informacional para as imagens oriundas de diversas disciplinas acadêmicas, o que acarreta na lacuna de pesquisa sobre as plataformas de periódicos eletrônicos nessa perspectiva.

Percebe-se que o Sistema Eletrônico de Editoração de Revistas (SEER) - software que predomina no cenário brasileiro na criação de periódicos digitais - possibilitou um avanço extremamente significativo na disponibilização do conhecimento produzido nas universidades (IBICT, 2020). ${ }^{5}$, mas ainda possui lacunas em relação a alguns tipos de produção, como as

\footnotetext{
3 O termo é utilizado para demonstrar que, simultaneamente, existem questões comunicacionais e problemas informacionais, duas dimensões diferentes do acesso digital aos artigos de periódicos.

${ }^{4}$ Foi feita uma revisão bibliográfica exploratória no Google Scholar, no Scielo, no Periódicos Capes, no ERIC e na Biblioteca Digital Brasileira de Teses e Dissertações. Não foram encontrados artigos que falem especificamente sobre revistas científicas nessa área, somente artigos que tangenciam o tema dentro de outros escopos.

${ }^{5}$ Sobre o SEER, segue um breve histórico disponibilizado no site do IBICT: "O Sistema de Eletrônico de Editoração de Revistas (SEER) é resultado da prospecção tecnológica realizada pelo IBICT para identificar aplicativos que possibilitassem o tratamento e a disseminação da produção científica brasileira na $W e b$. O sistema SEER surgiu, assim, em 2003, a partir da customização do Open Journal Systems (OJS), software de gerenciamento e publicação de revistas eletrônicas desenvolvido pelo Public Knowledge Project (PKP), da University of British Columbia. (...) A partir de então, o IBICT iniciou o processo e distribuição do SEER a editores brasileiros interessados em publicar revistas científicas de acesso livre na $W e b$ e a promover a capacitação técnica no uso dessa ferramenta, em treinamentos sistemáticos
} 
fotoetnográficas. Entendendo que a fotoetnografia resulta em trabalhos de campo onde a imagem deixa de ser mera ilustração e passa a ser a centralidade da pesquisa (ACHUTTT; HASSEN, 2004, p. 276), entende-se que a construção de periódicos digitais nessa área específica demonstra uma importante reflexão para o desenvolvimento desse campo do saber. Por isso, esse artigo trará alguns dos desafios inerentes às pesquisas feitas com recursos fotográficos a partir do relato de experiência da fundação e desenvolvimento da revista Fotocronografias ${ }^{6}$.

No cenário de emergência de vários periódicos de Antropologia Visual, será destacada a revista Fotocronografias pelo fato do autor deste artigo pertencer ao corpo editorial da mesma desde 2016 - momento de sua criação - e por ter contribuído à construção do processo editorial no que tange aos seus aspectos infocomunicacionais. A partir da experiência na fundação desse espaço de publicação a essa subárea de pesquisa em Antropologia, escrever-se-á sobre os desafios de criar uma proposta que misture o artigo científico com a expografia digital.

\section{NOTAS SOBRE AS QUESTÕES TEÓRICO-METODOLÓGICAS}

É importante mencionar algumas questões teórico metodológicas que guiaram a construção desse artigo, aspectos que não poderiam ser separados da trajetória do autor que aqui escreve. Participou-se ativamente de todas as reuniões que deram origem ao processo de construção da revista, e, por isso, esse paper foi escrito como um relato de experiência. Para isso, foi utilizada a Etnografia da Duração (ECKERT; ROCHA, 2013) para acessar a própria memória do autor a fim de narrar os fenômenos a partir de uma experiência pessoal. Ainda assim, salientase aos leitores que a Etnografia da Duração é um complexo processo de pesquisa que vai muito além do que aqui se explora neste artigo, já que se utiliza apenas algumas facetas teóricometodológicas deste tipo de etnografia para guiar a construção narrativa.

Em suma, o que importa é que esse relato não será feito para concretizar uma descrição fidedigna do que ocorreu no passado. Ao invés disso, será feita uma bricolagem das memórias do autor que serão reunidas para narrar esse percurso a partir do tempo presente. Atualmente, quem aqui escreve realiza pesquisa na área da Comunicação onde se estuda os problemas informacionais e comunicacionais relacionados com a comunicação científica do patrimônio das pesquisas em Antropologia Visual do grupo chamado Banco de Imagens e Efeitos Visuais (BIEV). Claramente,

realizados a partir de novembro de 2004 em várias regiões do País. Em 2009, com apenas 5 anos de existência, o SEER propiciou a criação de mais de 800 periódicos científicos brasileiros na $W e b . "$

${ }^{6}$ A revista pode ser acessada em: https://medium.com/fotocronografias 
esse olhar é mergulhado por essa pesquisa interdisciplinar em desenvolvimento hoje, fazendo com que as lembranças aqui resgatadas sobre a Fotocronografias estejam em uma dialética entre o que se pensa agora e o que se lembra sobre o que pensávamos em grupo em outros momentos.

\section{A REVISTA FOTOCRONOGRAFIAS: UMA BREVE APRESENTAÇÃO}

Em 2016, iniciou-se o processo de construção da revista Fotocronografias. Esse projeto foi idealizado pelo grupo BIEV em parceria com o Núcleo de Antropologia Visual (Navisual). Ambos os grupos são pertencentes ao Programa de Pós-Graduação em Antropologia Social (PPGAS) da Universidade Federal do Rio Grande do Sul (UFRGS). Como áreas temáticas de estudo, os grupos concentram suas pesquisas nas áreas da Antropologia Visual e da Imagem, da Antropologia Urbana, da Antropologia do Imaginário e do uso de novas tecnologias digitais para criação de projetos nas humanidades (ECKERT; ROCHA, 2015).

O BIEV foi fundado oficialmente em 1997 e, como forma de comunicar os seus resultados de pesquisa em parceria com o Navisual, criou a revista Iluminuras ${ }^{7}$ nos anos 2000. Essa foi a segunda revista eletrônica a focar a Antropologia Visual no Brasil, sucedendo apenas a revista Studium $^{8}$ da Unicamp que foi fundada em 1999 sob coordenação de Fernando de Tacca (ECKERT; ROCHA, 2016, p. 292). Com o desenvolvimento dos sistemas eletrônicos e digitais nas duas primeiras décadas do século XXI, inúmeras revistas online foram sendo criadas com foco nessa área temática como a Gesto, Imagem e Ação (GIS), a Visagem, a PROA, entre tantas outras.

Dentre essas emergentes propostas de periódicos científicos digitais, surge a revista Fotocronografias como um ambiente de publicação suplementar à revista Iluminuras no BIEV. Ela foi criada após uma série de discussões que foram feitas em grupo ao longo de 2015 e 2016 sobre a existência de especificidades em relação às formas de publicação do conhecimento produzido pelos pesquisadores da área da Antropologia Visual. De forma mais específica, começou a se pensar nas formas de publicação das fotoetnografias feitas por pesquisadores do Brasil, repensando os desafios de comunicação deste tipo de pesquisa em plataformas de periódicos eletrônicos.

A revista começou com a publicação de duas edições por ano e, atualmente, se consolidou com a publicação quadrimestral. É importante mencionar que se trata de uma revista que trabalha

\footnotetext{
${ }^{7}$ Para ver mais, acesse: https://seer.ufrgs.br/iluminuras

8 A Revista Studium merece destaque por ser uma das primeiras a criar um periódico que deu centralidade para o lugar da fotografia como escrita etnográfica, priorizando essa produção visual independentemente do texto escrito. Acesse em: https://www.studium.iar.unicamp.br
} 
especificamente com a fotografia dentro da Antropologia Visual, não aceitando artigos que abordem outras mídias como o audiovisual, o som ou o desenho. Para isso, a Fotocronografias possui uma proposta diferenciada de artigo que foi feita para dar centralidade às fotografias no seu processo editorial de comunicação científica das pesquisas nessa área. Cada artigo deve possuir entre dez a vinte fotografias enumeradas conforme a ordem de aparecimento ao(à) leitor(a), não sendo possível publicar sem que haja um processo de seleção e montagem do que deve ser exposto ao público da revista.

Outra norma importante de ser salientada no processo editorial é o tamanho das contribuições textuais que acompanham as imagens. O artigo sempre deve ser composto por um texto de 3000 a 6000 caracteres (contando espaços e referências bibliográficas) e um resumo de no máximo 500 caracteres (contando espaços). Essa escolha foi feita deliberadamente para que o centro da produção sejam as fotografias e não o texto, já que normalmente os ensaios fotográficos da Antropologia Visual não possuem um espaço para que sejam publicados sem a sua submissão hierárquica à escrita. Ainda assim, os textos devem conter uma síntese do que guia aquela pesquisa fotoetnográfica, realizando uma contextualização do trabalho de campo e das referências acadêmicas que guiam o processo de produção científica que está sendo submetido à revista.

Apesar da base deste periódico digital ser a fotoetnografia feita por antropólogos(as), a revista aceita contribuições de outras áreas do saber por entender que a Antropologia Visual e a área da fotografia dialogam com diversos campos de produção. É comum na área existir produções conjuntas com artistas visuais, com profissionais da comunicação ou mesmo com pessoas que não possuem uma ligação estreita com a carreira acadêmica (como os próprios parceiros de pesquisa que, muitas vezes, se tornam co-autores). Por isso, a revista salienta nas suas normas que várias pessoas para além do campo acadêmico da Antropologia podem participar das edições, desde que tenham uma contribuição considerada interessante à área da fotoetnografia pelos pareceristas.

Como várias outras revistas, a Fotocronografias trabalha com dossiês temáticos que atraem trabalhos para publicação. Contudo, após receber e avaliar todos os artigos recebidos, cada um deles passa por um processo de editoração específico que foi criado durante os últimos anos. É feito um processo editorial padronizado na plataforma digital que hospeda o site atualmente que expõe as fotografias a partir do que foi pensado pela Comissão Editorial. Cada ensaio é publicado em dois formatos: 1) um completamente digital para que as fotografias sejam acessadas em boa qualidade a partir da interatividade das redes digitais; 2) outro em formato de fotolivro digital que contém todos os artigos e ensaios fotográficos reunidos. 
A estabilização dessa padronização foi feita a partir de uma série de discussões realizadas nos últimos anos. A seguir, adentrar-se-á no relato da experiência dessas discussões que levantaram os problemas a serem enfrentados pelo grupo de pesquisa. 
Imagem 1 e 2 - Respectivamente, capa e contracapa do v. 7, n. 15 da revista Fotocronografias. Fonte: DOMINGUES; ERICK, CERVO, 2021.
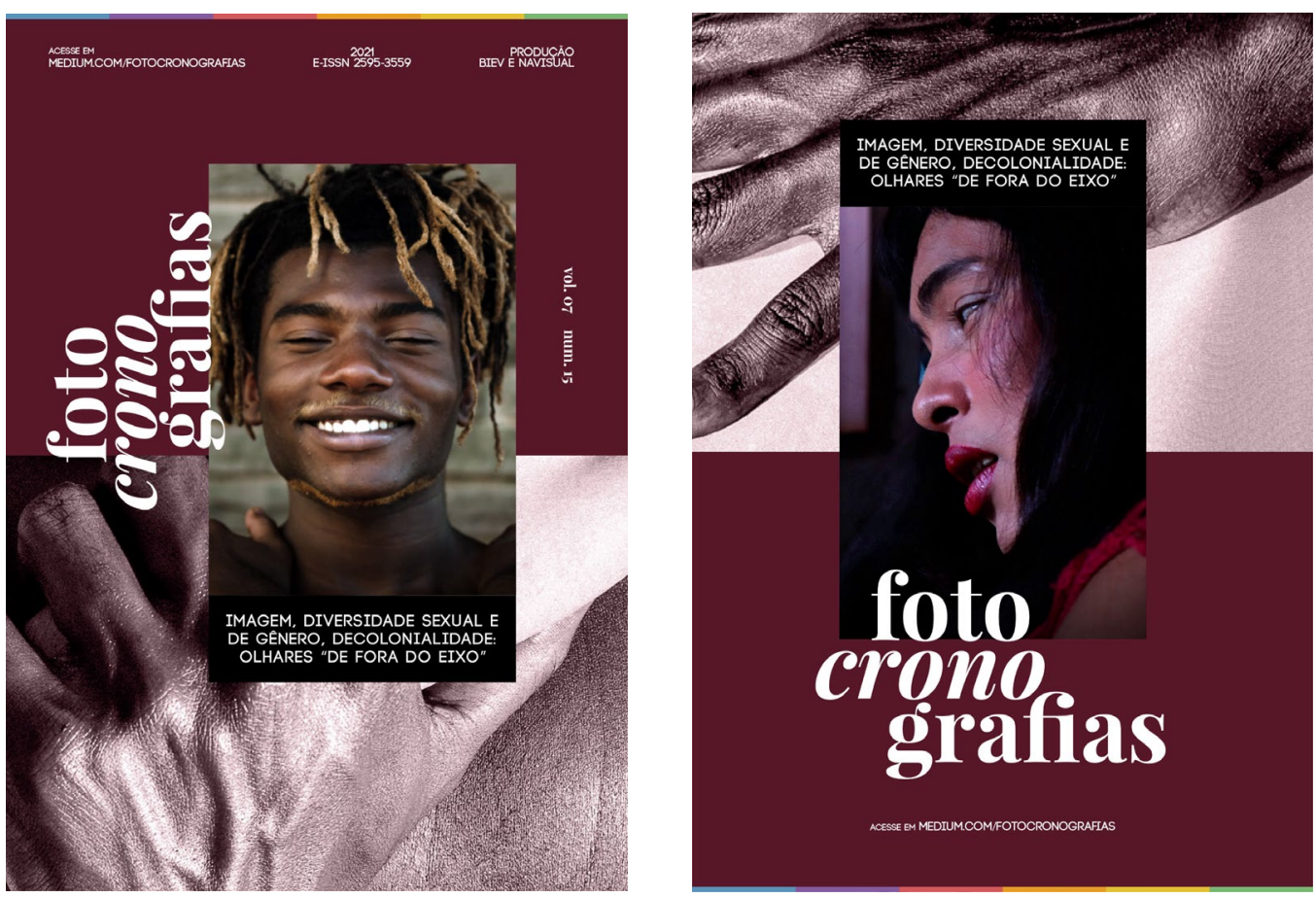

Imagem 3 - Fotografias em mosaico apresentadas na

edição em PDF do v. 07, n. 15 da revista Fotocronografias. Fontes: NETTO; CARDOSO; SANTOS, 2021

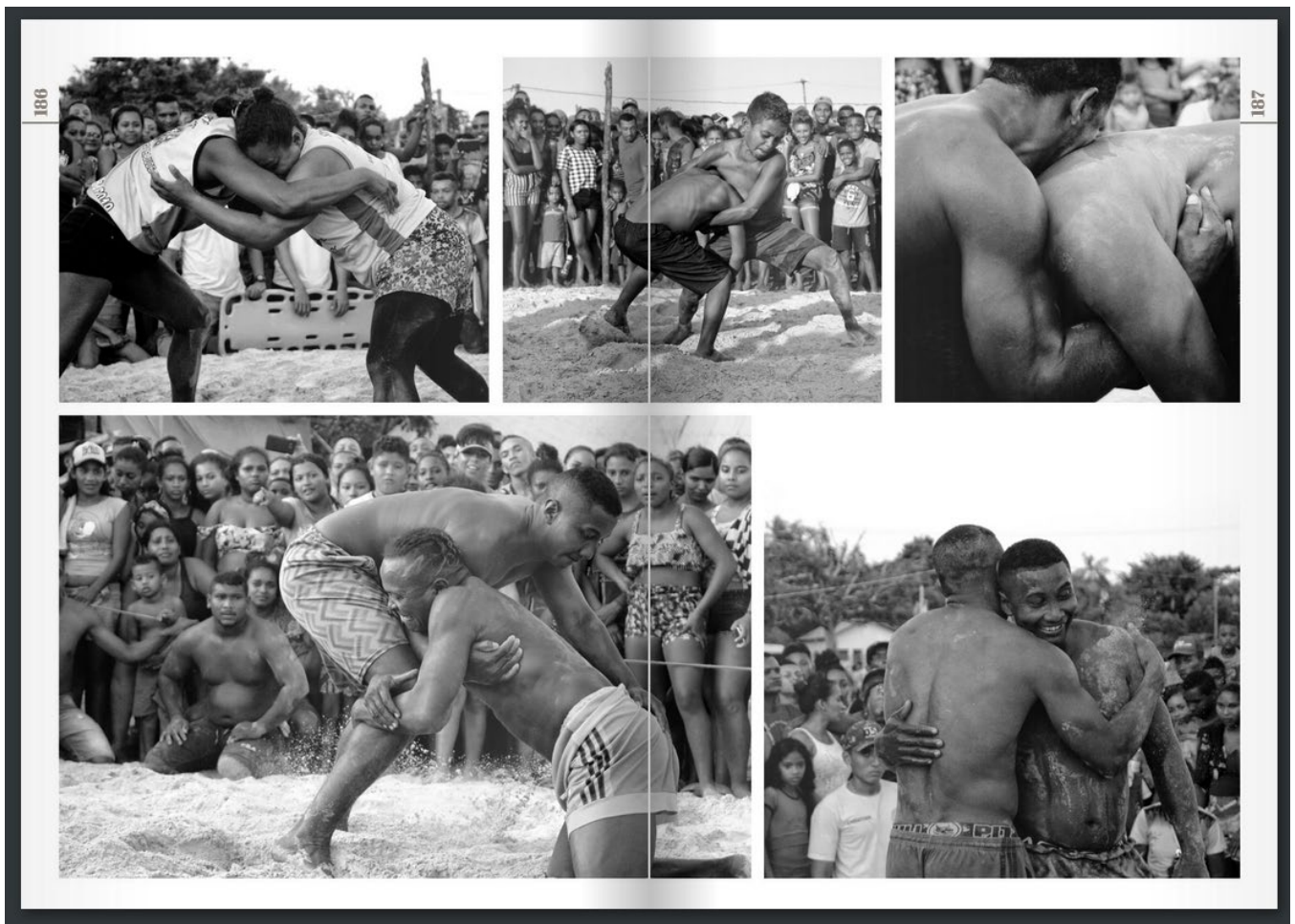




\section{BASES FUNDADORAS E DISCUSSÕES EM GRUPO}

Como mencionado anteriormente, a revista surge em 2016 após uma série de discussões que estavam acontecendo naquele ano com os membros que participavam do BIEV naquela época. No entanto, as discussões não surgiram de forma isolada de um contexto específico. Alguns eventos importantes promovidos pelos grupos de pesquisa que trabalham com Antropologia Visual na UFRGS estavam acontecendo e que podem ser mencionados para uma contextualização maior dos fenômenos. ${ }^{9}$

Alguns anos antes da concretização da revista, foi realizado um projeto de pesquisa vinculado ao $\mathrm{CNPq}$ a partir da professora Cornelia Eckert que foi intitulado como "Etnografias compartilhadas: narrativas visuais e sonoras do viver urbano em Porto Alegre (RS, Brasil), 2013 e 2014". Essa atividade de pesquisa coletiva foi coordenada pelo Navisual e foi encerrada em 2015 com uma exposição na Galeria Olho $\mathrm{Nu}$ - uma galeria que existe no Instituto de Filosofia e Ciências Humanas (IFCH) da UFRGS. Posteriormente, os resultados dessa pesquisa foram comunicados em exposições na Reunião Equatorial de Antropologia / Reunião de Antropologia do Norte e Nordeste (REA, ABANNE) de $2015^{10}$ e no $40^{\circ}$ Encontro Anual da Associação Nacional de Pós-Graduação e Pesquisa em Ciências Sociais (Anpocs) em 2016. ${ }^{11}$.

Em 23 de agosto de 2016, foi inaugurada a exposição presencial intitulada "Etnografias compartilhadas: narrativas visuais e sonoras do viver urbano em Porto Alegre" com apoio do centro de Difusão Cultural da UFRGS. Essa exposição foi fruto de vários projetos etnográficos e visuais feitos por uma turma de estudantes da disciplina de graduação sobre Antropologia Visual no primeiro semestre deste ano. Foram feitas nove etnografias urbanas em Porto Alegre e na região metropolitana com recursos fotográficos e sonoros que foram orientadas por pesquisadores do BIEV e do Navisual. Esses processos de orientação deram origem não só a bases de dados dessas pesquisas feitas na cidade, como também a um processo de seleção e montagem para comunicação do grande material de pesquisa a um público específico que poderia acessar essas pesquisas nesta exposição.

Olhando hoje para essa trajetória, acredita-se que todo esse cenário de produção expográfica auxiliou o grupo a começar a pensar como esses processos de comunicação científica

\footnotetext{
${ }^{9}$ É importante mencionar como contextualização que o BIEV já trabalhava com recursos eletrônicos e digitais de diferentes formas desde a sua fundação. Trabalhou por 20 anos com a hipertextualidade e a intertextualidade como novas formas de comunicar as pesquisas antropológicas feitas em contextos metropolitanos através de diferentes sites, blogs, DVDs interativos, entre outros. Nessas produções, o digital sempre foi aproveitado como forma de dar autonomia à narrativa fotográfica.

10 Acesse em: https://evento.ufal.br/anaisreaabanne/

${ }^{11}$ Acesse em: https://www.anpocs.com/index.php/40o-encontro-anual-2016
} 
feitos nesses ambientes presenciais poderiam ser, de alguma forma, pensados nas plataformas digitais que hoje se utiliza. No início das discussões, a escolha de criar um novo periódico que fosse além do que permite a revista Iluminuras não era um debate claro para os membros do grupo, já que isso foi se tornando uma possibilidade ao longo dos meses de concretização da Fotocronografias. Essa perspectiva claramente estava no horizonte das discussões, mas o que se colocava como objetivo central era a exposição das fotografias em algum site para realizar uma comunicação que atingisse um público mais amplo do que o presencial permite.

Em outras palavras, estava presente o desafio de realizar ações de difusão do conhecimento fotoetnográfico, e, por isso, o grupo começou a realizar reuniões semanais para pensar nesse projeto digital. Em certos momentos, alguns membros do BIEV traziam sites de outras revistas sobre fotografia como forma de mostrar o que se estava almejando. Um dos projetos que foi visto como referência e que foi levado como pauta de discussão em várias reuniões foi a revista Icônica.. ${ }^{12}$ Trata-se de um canal de publicação independente que era destinado à crítica de fotografia, arte e cultura em geral e que contou com apoio do Programa de Ação Cultural de São Paulo (ProacSP) e da Secretaria de Cultura do mesmo estado. O primeiro artigo publicado nessa revista data de 2009 e o último de 2018, havendo quase 10 anos de experiência neste projeto. Apesar de não ser da área da Antropologia especificamente, a construção da Icônica interessava ao grupo.

Achou-se interessante que a revista possuía um ISSN e era organizada por professores e pesquisadores que são doutores como Claudia Linhares Sanz, Didiana Prata de Lima Barbosa, Mauricio Lissovsky - entre vários outros que são mencionados no site da revista. Contudo, mesmo possuindo o Número Internacional Normalizado para Publicações Seriadas - o que confere um estatuto de periódico científico aos artigos publicados em certas seções -, ela não se restringia às formas de publicação consolidadas no nosso sistema digital no Brasil com a plataforma SEER. A partir de um site independente, foi construído um design para web específico que permitia uma proposta narrativa dos artigos críticos diferente e pouco usual nas revistas acadêmicas.

Existem vários aspectos que foram considerados interessantes durante nossas reuniões, mas salienta-se o mais importante para construção dos argumentos que aqui se realiza. Ao entrar nos artigos escritos, percebia-se que não havia o acesso a eles através dos consolidados arquivos Portable Document Format (PDF), situação que é padrão nos periódicos eletrônicos construídos com a plataforma SEER no Brasil. Todos os artigos foram criados no próprio site a partir de uma linguagem simples que é a Linguagem de Marcação de HiperTexto (HTML), permitindo que texto e fotografia (além de outras mídias no caso desta revista) fossem entrelaçados de outra forma que não é possível nos documentos PDF.

${ }^{12}$ Acesso em: https://www.iconica.com.br/site/tag/revistas/ 
Isso se deve não só a uma questão estética de montagem, como também ao acesso às fotografias em boa resolução, visto que é possível clicar e abrir as imagens devido à interatividade própria de sites simples como o desta revista - o que é impossível em outros tipos de arquivos como os tradicionalmente usados nos periódicos eletrônicos. Ao longo do tempo e das discussões, foi se percebendo que isso era uma preocupação de algumas revistas da própria Antropologia Visual também. Um dos exemplos disso é a Studium já aqui mencionada, posto que ela também criou um site independente onde os artigos são construídos em formato HTML em que as imagens podem ser abertas com boa resolução. Porém, é interessante perceber que, talvez como estratégia de adequação ao sistema de publicação digital mais consolidado, a Studium criou um sistema híbrido em que estão disponíveis tanto os artigos em formato HTML quanto coletâneas de artigos reunidas no formato PDF.

Além desses projetos nacionais, debateu-se um site da Burn Magażine. ${ }^{13}$ - uma referência internacional na área da fotografia. A Burn é uma revista digital que iniciou em 2008 com a intenção de criar uma rede de fotógrafos para educação nesta área de atuação, agrupando inúmeros profissionais que, de alguma forma, trabalham com a fotografia no seu campo. Apesar de não ser uma revista que tem caráter de produção acadêmica como as outras aqui citadas, o projeto foi importante para as reflexões do grupo pela forma como trazia os ensaios fotográficos em um site específico para o projeto.

Em primeiro lugar, a plataforma chamou a atenção de alguns membros do BIEV porque utilizava o "mosaico" como forma de exibição das fotografias dos ensaios enviados à revista. A palavra mosaico é utilizada aqui para se referir à exposição de imagens em sites a partir de colunas e linhas onde as fotografias aparecem com tamanhos diferentes, compondo um todo. Assim sendo, é possível perceber cada fotografia na sua individualidade, mas sem nunca a perceber isolada do seu contexto total de produção e do encadeamento cronológico próprio da fotoetnografia.

Essa foi uma das maiores discussões que se fez na época, já que se pensava também no trabalho realizado pelo BIEV com a Etnografia da Duração. Foi com essas intenções que foi dada, pela professora Cornelia Eckert, a ideia do nome Fotocronografias ao projeto de comunicação digital que estava sendo criado, visto que a intenção era deixar transparecer o chronos - ou seja, o tempo próprio do trabalho fotoetnográfico - nesse encadeamento de imagens. Desta forma, era possível orientar a estética do projeto que estávamos criando para que ele estivesse alinhado às pesquisas e teorias que dão base para as produções etnográficas do BIEV (ECKERT; ROCHA, 2013).. ${ }^{14}$

\footnotetext{
13 Acesso em: https://www.burnmagazine.org

14 A base da discussão que guiou a construção dessa revista sobre fotoetnografia ligada à questão temporal é a Etnografia da Duração citada acima no corpo do texto, uma forma de estudar a memória no contexto das sociedades complexas pela Antropologia Urbana.
} 
Além disso, esse tipo de "exposição" em mosaico nos sites se aproximava bastante da experiência expográfica construída ao longo dos anos pelos grupos de pesquisa em Antropologia Visual da UFRGS. Mas, diferente de um fotolivro que poderia reproduzir no formato livresco o que há nessas exposições, é possível clicar nas fotografias e as ver de forma isolada em grande resolução nesses mosaicos digitais, possibilitando a recuperação dos documentos fotográficos em alta qualidade como nos outros sites analisados no processo de produção. Assim sendo, foram consolidadas as bases do que se estava buscando na concretização desta plataforma que hospedaria os ensaios visuais deste novo projeto.

\section{PRIMEIROS NÚMEROS E CONSOLIDAÇÃO DO MODELO}

Foram com essas discussões consolidadas que iniciamos o processo de construção do site. A primeira tentativa foi construir um site em Wordpress, mas se percebia que seria mais acessível, naquele momento de produção, concretizar o projeto em uma plataforma mais simples que permitisse que a maior parte da equipe do BIEV tivesse alguma atuação. ${ }^{15} \mathrm{Com}$ isso, escolheu-se o Medium que é uma plataforma de publicação em formato de blog, mas que possui mais recursos para construção de projetos como o que estávamos almejando ${ }^{16}$. Além disso, o BIEV já estava experimentando a plataforma com a criação do projeto Livro do Etnógrafo ${ }^{17}$, um blog com postagens variadas e autorais sobre como fazer etnografia.

Foi criada uma identidade visual para a Fotocronografias. Não só foi feito um logotipo que identifica até hoje a revista, como também foi construída a padronização do processo editorial como foi mencionado anteriormente. Neste momento, foram delimitados o desenho das capas das edições, o layout em mosaico dos artigos dispostos no medium, a editoração dos fotolivros digitais em formato PDF, o uso de tipografias específicas, entre vários outros aspectos relacionados com o campo da Comunicação. Tudo foi feito com a intenção de criar uma proposta visual que comunicasse de forma específica os trabalhos que compõem os números deste periódico.

Neste momento, já era consenso que não se faria a construção desse projeto no SEER oferecido pela universidade, porque não havia nenhum suporte para produções imagéticas nesse tipo de plataforma. Todas as discussões que foram feitas sobre a necessidade de criar um processo

\footnotetext{
${ }^{15}$ Essa decisão também foi tomada devido ao espaço que ocupam as fotografias com boa resolução em um servidor próprio. Como dependia-se de um servidor oferecido pela universidade, o espaço concedido não era suficiente para criação do projeto - uma questão sempre proeminente.

${ }^{16}$ Medium é um site para publicações que foi fundado pelo co-fundador do Twitter, Evan Williams, em agosto de 2012. Como um serviço, possui recursos gratuitos e recursos pagos.

17 Acesso em: https://medium.com/livrodoetnografo
} 
editorial específico se tornariam impossíveis com a implementação da revista no sistema padrão para criação de periódicos na UFRGS. Por isso, no início da construção do site, haviam controvérsias acerca do estatuto da Fotocronografias como um periódico científico, já que ela poderia apenas se tratar de um projeto de comunicação digital que não seria de fato uma publicação formal e seriada.

Nesse sentido, as primeiras edições da revista realmente foram experimentais. As duas exposições que foram mencionadas anteriormente deram material fotográfico suficiente para que fossem feitas experiências iniciais, o que resultou nos dois primeiros números da revista publicados em 2016. Neste momento, não havia ainda todo o processo de criação de dossiês com as exigências que existem atualmente, mas foi possível criar dois números que contém todo material (tanto fotográfico quanto textual) das exposições que foram realizadas. Isso permitiu que novas reflexões surgissem para as próximas edições e que fossem comunicadas as fotografias (e informações gerais) sobre essas exposições a um público mais amplo.

Em 2017, houve mais uma publicação de uma exposição fotográfica chamada "Carta aos Narradores Urbanos: Etnografia de Rua na Porto Alegre das Intervenções Artísticas”. ${ }^{18}$. Essa foi uma grande exposição organizada por professores e pesquisadores ligados ao Navisual onde foram homenageados nove "narradores urbanos" a partir de cartas que foram escritas a esses autores que inspiram as produções feitas pela Antropologia Visual da UFRGS. A partir de quatro saídas de campo em quatro diferentes territorialidades de Porto Alegre, foram fotografadas intervenções artísticas que compõem a paisagem urbana da nossa cidade. Feito o trabalho de etnografia de rua (ECKERT; ROCHA, 2013b), foram selecionados oito conjuntos de fotografias que acompanharam as cartas aos narradores urbanos na expografia.

Novamente, essa exposição foi feita em parceria com o programa de extensão do Departamento de Difusão Cultural da UFRGS e sob a curadoria do técnico administrativo e antropólogo Rafael Derois dos Santos. Após a sua exposição em ambiente presencial, o material foi aproveitado para criar a terceira edição da revista Fotocronografias. ${ }^{19}$, número em que se avançou na construção dos ensaios fotográficos junto dos textos das cartas que foram redigidas às exposições. Esse foi o último número da revista que não teve propriamente um processo padronizado como periódico acadêmico, já que o segundo número publicado em 2017 foi uma primeira experiência com o recebimento de artigos propriamente ditos.

\footnotetext{
18 Acesso em: https://medium.com/fotocronografias/v-02-n-03-2017-cartas-aos-narradores-urbanos-etnografia-derua-na-porto-alegre-das-97185561d64e

${ }_{19}$ Acesso em: https://medium.com/fotocronografias/v-02-n-03-2017-cartas-aos-narradores-urbanos-etnografia-derua-na-porto-alegre-das-97185561d64e
} 
Trata-se do volume 02, número 04 que se chama "A memória afetiva de lugares e pessoas: quando as imagens testemunham" ${ }^{20}$. Esse volume foi organizado pelas professoras coordenadoras do BIEV, Ana Luiza Carvalho da Rocha e Cornelia Eckert, e contou com a participação de dois autores externos ao grupo: Pamela Jorquera com fotografias da sua tese de doutorado em Inca do Ouro e Luiz Eduardo Robinson Achutti com sua fotoetnografia feita em Cuba, Havana. Mesmo tendo um aspecto experimental por ter apenas dois artigos que carecem de algumas normatizações que a revista possui atualmente após seu processo de amadurecimento, esse foi um importante número. Afirma-se isso porque começou a se perceber a importância de não manter a plataforma restrita à comunicação de trabalhos fotográficos, posto que estava sendo iniciado um trabalho propriamente de revista acadêmica com a organização de dossiês.

Foi em 2018 que a revista teve os seus dois primeiros números consolidados com todos os processos próprios de um periódico digital e com normas para publicação estabilizadas. O volume 03, número 05 chamado "A arte que mora na cidade: intervenções artísticas urbanas" ${ }^{21}$ organizada por Jose Luis Abalos Junior e Yuri Rosa Neves marcou a inauguração do formato que é seguido até hoje pela revista. Foi feita uma chamada para esse dossiê temático sobre fotoetnografia e intervenções artísticas feitas nas cidades e, após receber os artigos com as normas já estabelecidas, as produções passaram pelos pareceristas que contribuíram com uma avaliação específica deste novo tipo de artigo.

Foi nesse número que os organizadores começaram a escrever uma apresentação da edição como em outros periódicos, assim como foi nesse momento que as produções recebidas passaram a ser padronizadas. A partir disso, os textos que acompanham as fotografias passaram a ser originais e começou a ser exigido que referências bibliográficas utilizadas no percurso de pesquisa acadêmico fossem obrigatórias em alguma medida. Isso se deve ao fato de que o grupo passou a perceber a importância de consolidar esse projeto como uma nova proposta de periódico acadêmico, debate que começou a ter mais ressonância principalmente a partir da experiência com o segundo número lançado em 2017.

É interessante notar que, se antes o grupo não sabia se queria exatamente uma plataforma para publicação formal de artigos científicos, a formalização como periódico acadêmico se tornou consenso em 2018. Ao longo das experiências que houve nos dois primeiros anos, foi sendo percebida a importância de não abdicar do estatuto de periódico científico devido à construção de uma revista de Antropologia que contém produções que vão além da escrita. Além disso, foi se

\footnotetext{
${ }^{20}$ Acesso em: https://medium.com/fotocronografias/v-02-n-04-2017-a-mem\%C3\%B3ria-afetiva-de-lugares-epessoas-quando-as-imagens-testemunham-910c148984b

${ }_{21}$ Acesso em: https://medium.com/fotocronografias/v-03-n-05-2018-a-arte-que-mora-na-cidadeinterven $\% \mathrm{C} 3 \% \mathrm{~A} 7 \% \mathrm{C} 3 \% \mathrm{~B} 5$ es-art $\% \mathrm{C} 3 \%$ ADsticas-urbanas-bde 473181254
} 
percebendo que, para manter um fluxo de contribuições, seria importante desenvolver a formalidade para que as publicações fossem avaliadas de forma mais simétrica em relação às produções escritas dentro da academia. A possibilidade de desenvolver uma revista com outra forma de avaliação e editoração que centralizasse a produção fotográfica de pesquisas universitárias se tornou, paulatinamente, real.

Assim sendo, o primeiro número de 2018 resultou na aquisição do e-ISSN à Fotocronografias. Progressivamente, a revista consolidou o seu modelo de produção ao longo dos anos e começou a produzir mais números com esse formato específico para publicação de fotoetnografias. Em 2019, houve quatro números que foram organizados por professores e pesquisadores do BIEV e do Navisual. Esse ano foi especialmente importante porque, após a consolidação deste modelo de produção e publicação, percebeu-se que havia uma demanda razoável para envio de ensaios fotográficos provenientes de pesquisas acadêmicas, possibilitando a publicação de quarenta artigos nesses quatro números. Por isso, a revista passou a produzir com regularidade quadrimestral.

Essa demanda não era só por publicação, mas também por pesquisadores interessados em organizar dossiês à revista. Antes de 2020, os números eram exclusivamente organizados por pesquisadores do BIEV e do Navisual devido ao processo de consolidação das publicações no modelo criado à Fotocronografias. Não obstante, a partir de 2020, os números começaram a ser organizados por outros(as) pesquisadores(as) como Claudia Ribeiro, Fabiene Gama, Marielen Baldissera, Thayanne Freitas, Hermes de Souza Veras, Guillermo Stefano Rosa Gómez, Luísa Dantas e Manoel Rocha.

Foi nessa experiência que o grupo da Comissão Editorial percebeu a necessidade de acompanhamento de algum membro do BIEV durante toda produção desses dossiês, já que a Fotocronografias possui um tipo de editoração específica que já foi aqui explicitada. Além da participação de algum membro na organização, a revista continua com a atuação voluntária de profissionais da área da Comunicação a fim de manter a padronização do processo editorial e artístico criado à revista. Esse aspecto é considerado fundamental, já que a produção desse periódico não consegue durar no tempo sem uma equipe que seja composta por pesquisadores e profissionais de diferentes áreas do conhecimento.

\section{CONCLUSÕES}


Esse artigo elencou alguns dos desafios que foram mapeados durante as discussões que deram origem à revista Fotocronografias e dos anos de contínuo desenvolvimento desta revista acadêmica sobre Antropologia Visual. Conclui-se que, atualmente, há um desafio importante neste cenário de produção que é a construção de redes interdisciplinares para consolidação de projetos como esse. Percebe-se que são necessárias diferentes competências profissionais para atuar nas diversas facetas de revistas universitárias que possuem como escopo a aquisição, a avaliação e a comunicação de trabalhos que são acadêmicos e que não se restringem à escrita científica.

Como dito neste artigo, muitos desafios se referem aos aspectos infocomunicacionais destas produções, já que as plataformas consolidadas para publicação de periódicos eletrônicos possuem estrutura informacional específica para artigos escritos. Isso não se deve somente à estética da comunicação - que também é fundamental -, mas também aos aspectos do acesso aos documentos fotográficos digitais com qualidade alta, possibilitando a transferência de informações na internet de forma adequada. Comumente, fala-se sobre a importância de plataformas de periódicos científicos não só pela abertura gratuita da ciência a todas as pessoas interessadas, mas também pela preservação dos arquivos digitais - e isso também deve ser pensado às fotoetnografias.

Por isso, a conclusão mais importante deste artigo é perceber que a Fotocronografias caminhou na direção da resolução de alguns destes problemas, mas está claro que existem inúmeros outros que apenas uma caminhada mais longa poderia elencar. Como exemplo disso, nos últimos anos, o BIEV percebeu a importância da construção de documentação padronizada sobre os registros multimídia feitos por pesquisadores que passaram pelo grupo. Isso se deve à necessidade de preservação digital que vá além dos arquivos em si, visto que é necessário haver metainformação que fale sobre os documentos e contextualize uma série de dados pertinentes à pesquisa antropológica.

O mesmo pode ser dito para os registros fotográficos que são publicados nas revistas de Antropologia Visual. Afinal, para além de uma padronização condizente com as normatizações dos periódicos científicos atuais no Brasil, é importante perceber que outras normas podem ser criadas a fim de comunicar e preservar adequadamente os trabalhos fotoetnográficos que são feitos e publicados nestes suportes. Muitos outros problemas como esse podem ser elencados nessa área de pesquisa que ainda é pouco explorada. Por isso, para dar longa vida e expandir os já existentes 25 anos de fotoetnografia brasileira, acredita-se que precisamos de mais reflexões interdisciplinares sobre esse tipo de periódico científico. 


\section{Referências}

ACHUTTI, L.; HASSEN, M. Caderno de campo digital: antropologia em novas mídias. Horizontes antropológicos, v. 10, n. 21, 2004, 273-289. https://www.scielo.br/scielo.php?pid=S0104-71832004000100012\&script=sci arttext\&tlng=pt, acesso em 23/05/2021.

DOMINGUES, B.; ERICK, I.; CERVO, M. Imagem, diversidade sexual e de gênero, decolonialidade: olhares "de fora do eixo". Revista Fotocronografias, v. 07, n. 15, 2017. https://medium.com/fotocronografias/vol-07-num-15-2021-5a178ceb9f44, acesso em 19/05/2021.

ECKERT, C.; ROCHA, A. "Nunca en anexo!" Pesquisa, ensino e escrita con imagens em Antropología Audiovisual. Revista Trama, n. 11, 2020, pp. 10-32. http://www.auas.org.uy/trama/index.php/Trama/article/view/196, acesso em 19/05/2021.

ECKERT, C.; ROCHA, A. A memória afetiva de lugares e pessoas, quando as imagens testemunham. Revista Fotocronografias, v. 02, n. $\quad$ 04, 2017. https://medium.com/fotocronografias/v-02-n-04-2017-a-mem\%C3\%B3ria-afetiva-de-lugares-epessoas-quando-as-imagens-testemunham-910c148984b, acesso em 23/05/2021.

ECKERT, C.; ROCHA, A. A preeminência da imagem e do imaginário nos jogos da memória coletiva em coleções etnográficas. 1. ed. Brasília: ABA, 2015. v. 1. 196p. https://www.ufrgs.br/biev/livros-e-artigos-2/, acesso em 23/05/2021.

ECKERT, C.; ROCHA, A. Antropologia da Imagem no Brasil: experiências fundacionais para a construção de uma comunidade interpretativa. Revista Iluminuras, v. 17, n. 41, 2016, pp. 277 297. https://www.lume.ufrgs.br/bitstream/handle/10183/143517/000994561.pdf?sequence=1, acesso em 23/05/2021.

ECKERT, C.; ROCHA, A. Cartas aos narradores urbanos: Etnografia de rua na Porto Alegre das intervenções artísticas. Revista Fotocronografias, v. 02, n. 03, 2017. https://medium.com/fotocronografias/v-02-n-03-2017-cartas-aos-narradores-urbanosetnografia-de-rua-na-porto-alegre-das-97185561d64e, acesso em 23/05/2021.

ECKERT, C.; ROCHA, A. Etnografia da Duração: antropologias das memórias coletivas nas coleções etnográficas. Porto Alegre: Marcavisual, 2013. v. 1. 256p. https://www.ufrgs.br/biev/livros-e-artigos-2/, acesso em: 23/05/2021. 
ECKERT, C.; ROCHA, A. Etnografia de rua: Estudos de Antropologia Urbana. 1. ed. Porto Alegre: Editora da UFRGS e Editora Deriva, 2013. https://www.ufrgs.br/biev/livros-e-artigos$2 /$, acesso em 23/05/2021.

ECKERT, C.; ROCHA, A. Etnografias compartilhadas: narrativas visuais e sonoras do viver urbano em Porto Alegre. Revista Fotocronografias, v. 01, n. 01, 2016. https://medium.com/fotocronografias/edi $\% \mathrm{C} 3 \% \mathrm{~A} 7 \% \mathrm{C} 3 \% \mathrm{~A} 3 \mathrm{o}-\mathrm{n} \% \mathrm{C} 2 \% \mathrm{BA}-01$-etnografiascompartilhadas-c182f46b8225, acesso em 23/05/2021.

ECKERT, C.; ROCHA, A. Itinerância da Expografia - Na Porto Alegre da Copa, os ritmos de construção destrutiva ou destruição construtiva: oficina de etnografia audiovisual no Navisual, 2013 e 2014. Revista Fotocronografias, v. 01, n. $02,2016$. https://medium.com/fotocronografias/v-01-n-02-2016-itiner $\%$ C $3 \%$ A2ncia-da-expografia-naporto-alegre-da-copa-os-ritmos-de-constru $\% \mathrm{C} 3 \% \mathrm{~A} 7 \% \mathrm{C} 3 \% \mathrm{~A} 3 \mathrm{o}-\mathrm{b} 313 \mathrm{~d} 46 \mathrm{ecfe} 9$, acesso em 23/05/2021).

IBICT. Histórico do Sistema Eletrônico de Editoração de Revistas (SEER). Instituto Brasileiro de Informação em Ciência e Tecnologia, 2012. http://sitehistorico.ibict.br/pesquisadesenvolvimento-tecnologico-e-inovacao/sistema-eletronico-de-editoracao-de-revistasseer/historico, acesso em 13/05/2021.

JUNIOR, J.; NEVES, Y. A arte que mora na cidade: intervenções artísticas urbanas. Revista Fotocronografias, v. 03, n. 05, 2018. https://medium.com/fotocronografias/v-03-n-05-2018-aarte-que-mora-na-cidade-interven $\% \mathrm{C} 3 \% \mathrm{~A} 7 \% \mathrm{C} 3 \% \mathrm{~B} 5$ es-art $\% \mathrm{C} 3 \% \mathrm{AD}$ sticas-urbanasbde473181254, acesso em 23/05/2021.

NETTO, F.; CARDOSO, D.; SANTOS; P. Imagens de Campos - Apresentação fotoetnográfica dos jogos de identidade quilombola do Marajó. Revista Fotocronografias, v. 07, n. 15, 2021. https://medium.com/fotocronografias/imagens-de-campo-apresenta $\% \mathrm{C} 3 \% \mathrm{~A} 7 \% \mathrm{C} 3 \% \mathrm{~A} 3 \mathrm{O}-$ fotoetnogr $\% \mathrm{C} 3 \% \mathrm{~A} 1$ fica-dos-jogos-de-identidade-quilombola-do-maraj $\% \mathrm{C} 3 \% \mathrm{~B} 3$ - $7 \mathrm{bbdf0cdfcfc}$, acesso em 23/05/2021. 